\title{
Article \\ Efficacy of Lipid-Lowering Therapy during Cardiac Rehabilitation in Patients with Diabetes Mellitus and Coronary Heart Disease
}

\author{
Thomas Wittlinger ${ }^{1, *}$, Bernhard Schwaab ${ }^{2}$ (D) Heinz Völler ${ }^{3,4}{ }^{\text {, Christa Bongarth }}{ }^{5}$, Viktoria Heinze ${ }^{6}$, \\ Kristina Eckrich ${ }^{7}$, Manju Guha ${ }^{8}$, Michael Richter ${ }^{9}$ and Axel Schlitt ${ }^{6,10}$
}

check for

updates

Citation: Wittlinger, T.; Schwaab, B.; Völler, H.; Bongarth, C.; Heinze, V.;

Eckrich, K.; Guha, M.; Richter, M.; Schlitt, A. Efficacy of Lipid-Lowering Therapy during Cardiac Rehabilitation in Patients with Diabetes Mellitus and Coronary Heart Disease. J. Cardiovasc. Dev. Dis. 2021, 8, 105. https://doi.org/ $10.3390 /$ jcdd 8090105

Received: 18 June 2021

Accepted: 24 August 2021

Published: 30 August 2021

Publisher's Note: MDPI stays neutral with regard to jurisdictional claims in published maps and institutional affiliations.

Copyright: (c) 2021 by the authors. Licensee MDPI, Basel, Switzerland. This article is an open access article distributed under the terms and conditions of the Creative Commons Attribution (CC BY) license (https:// creativecommons.org/licenses/by/ $4.0 /)$.

\author{
Asklepios Harzkliniken GmbH, Kösliner Strasse 12, 38642 Goslar, Germany \\ Medizinische Fakultät, Universität zu Lübeck, D-23562 Lübeck, Germany; prof.schwaab@drguth.de \\ Department of Rehabilitation Medicine, Faculty of Health Sciences Brandenburg, University of Potsdam, \\ D-14469 Potsdam, Germany; Heinz.Voeller@klinikamsee.com \\ 4 Klinik am See, Department of Cardiology, 15562 Rüdersdorf, Germany \\ 5 Clinic Höhenried, 82347 Bernried, Germany; christa.bongarth@hoehenried.de \\ 6 Paracelsus-Harz-Clinic, 06485 Bad Suderode, Germany; viktoria.heinze@pkd.de (V.H.); \\ axel.schlitt@pkd.de (A.S.) \\ 7 Clinic Tharandter Wald—Hetzdorf, 09633 Halsbrücke, Germany; kemange@gmx.de \\ 8 Rehabilitation Clinic Sendesaal, 28329 Bremen, Germany; dr.guha@rehaklinik-sendesaal.de \\ 9 Coordination Center for Clinical Studies, Martin Luther-University Halle Wittenberg, 06120 Halle, Germany; \\ richter.michael@kks-halle.de \\ 10 Medical Faculty, Martin Luther-University, 06120 Halle Wittenberg, Germany \\ * Correspondence: dr.wittlinger@gmx.de
}

\begin{abstract}
Background: Cardiac rehabilitation (CR) in patients with coronary heart disease (CHD) increases adherence to a healthy lifestyle and to secondary preventive medication. A notable example of such medication is lipid-lowering therapy (LLT). LLT during CR improves quality of life and prognosis, and thus is particularly relevant for patients with diabetes mellitus, which is a major risk factor for CHD. Design: A prospective, multicenter registry study with patients from six rehabilitation centers in Germany. Methods: During CR, 1100 patients with a minimum age of 18 years and CHD documented by coronary angiography were included in a LLT registry. Results: In 369 patients (33.9\%), diabetes mellitus was diagnosed. Diabetic patients were older (65.5 \pm 9.0 vs. $62.2 \pm 10.9$ years, $p<0.001$ ) than nondiabetic patients and were more likely to be obese (BMI: $30.2 \pm 5.2 \mathrm{~kg} / \mathrm{m}^{2}$ vs. $\left.27.8 \pm 4.2 \mathrm{~kg} / \mathrm{m}^{2}, p<0.001\right)$. Analysis indicated that diabetic patients were more likely to show LDL cholesterol levels below $55 \mathrm{mg} / \mathrm{dL}$ than patients without diabetes at the start of CR (Odds Ratio (OR) 1.9; 95\% CI 1.3 to 2.9) until 3 months of follow-up (OR 1.9; 95\% CI 1.2 to 2.9). During 12 months of follow-up, overall and LDL cholesterol levels decreased within the first 3 months and remained at the lower level thereafter $(p<0.001)$, irrespective of prevalent diabetes. At the end of the follow-up period, LDL cholesterol did not differ significantly between patients with or without diabetes mellitus $(p=0.413)$. Conclusion: Within 3 months after CR, total and LDL cholesterol were significantly reduced, irrespective of prevalent diabetes mellitus. In addition, CHD patients with diabetes responded faster to LTT than nondiabetic patients, suggesting that diabetic patients benefit more from LLT treatment during CR.
\end{abstract}

Keywords: coronary heart disease; cardiac rehabilitation; diabetes mellitus; lipid-lowering therapy

\section{Introduction}

Diabetes mellitus constitutes a major risk factor for developing coronary heart disease (CHD), and potentiates the risk for fatal events in patients who already have CHD [1]. Standard treatment of CHD in patients with and without diabetes typically comprises a combination of lifestyle changes, e.g., physical activity on a regular basis, cessation 
of smoking, adoption of a healthier diet, and secondary preventive medication. The pharmacotherapy includes angiotensin-receptor blockers, ACE inhibitors, beta-blocking agents, and platelet inhibitors. A major goal in the treatment of diabetes mellitus is the reduction of blood lipid levels [2]. Here, lipid-lowering drugs represent one of the most important therapeutic interventions [3].

Currently, the medical consensus recommends lipid-lowering therapy (LLT) for all patients who have developed CHD, irrespective of whether they have diabetes [4,5]. This treatment is independent of the initial level of low-density lipoprotein (LDL) cholesterol. LLT aims to reduce the LDL cholesterol level below $55 \mathrm{mg} / \mathrm{dL}(1.4 \mathrm{mmol} / \mathrm{L})$ and/or to decrease the LDL cholesterol level by at least 50\% [6]. Since 2019, guidelines have recommended reducing LDL cholesterol to even less than $40 \mathrm{mg} / \mathrm{dL}$ in very high risk patients, for example, after a second CHD-related event [4].

The cornerstone of LLT is the administration of a maximum dose of statins, with a number of studies demonstrating that high-potency statins (e.g., atorvastatin, rosuvastatin) are superior to low-potency statins (e.g., pravastatin, simvastatin) [7-9]. However, some patients do not respond sufficiently to statin monotherapy. Moreover, statin therapy can cause severe adverse effects, such as myotoxicity, which occurs in the form of myopathy, myalgia, myositis, or rhabdomyolysis [10,11]. A recent study associated high doses of statins with an increased risk for osteoporosis [12]. The only available alternatives to statin monotherapy is combination therapy with either ezetimibe or inhibitors of proprotein convertase subtilisin/kexin type 9 (PCSK9) $[13,14]$. For example, combination therapy with ezetimibe and simvastatin was reported to reduce LDL cholesterol levels, to decrease adverse effects such as nonfatal myocardial infarction and stroke, and to lower the rates of cardiovascular death [15].

Compliance to medication often poses problems because high cholesterol levels go unnoticed, and patients may skip or even stop taking the drug [16,17]. Participation in cardiac rehabilitation (CR), however, leads to better adherence, and to a significant reduction in mortality among CHD patients [18]. Hence, CR is a fundamental component for successful long-term CHD treatment [19-21]. Data from almost 100,000 CHD patients enrolled in about 150 randomized trials have demonstrated the benefit of CR on both cardiovascular and total mortality [22,23]. Furthermore, many studies have established that CR improves quality of life as well [24,25]. In Germany, standard of care for CHD patients after ACS or CABG surgery comprises a multimodal 3-week CR at specialized rehabilitation centers $[18,24,26-28]$. This multimodal rehabilitation attempts to both optimize drug therapy and educate patients on the impact and possible adverse effects of drugs in order to increase compliance with drug treatment $[18,26-28]$. Additionally, CR commonly implements intensive programs on five days a week, including psychosocial support, physical exercise, and nutrition counseling [18].

In this analysis of the German multicenter Lipid-Lowering-Therapy-Rehabilitation registry (LLT-R), we focused on the effect of LLT in patients with diabetes mellitus and CHD. We interrogated to what extent CHD patients with diabetes mellitus benefit from LLT during CR.

\section{Methods}

\subsection{Study Design}

The LLT-R registry included 1100 patients who were admitted to one of the six participating German rehabilitation clinics. Inclusion criteria for this study were a minimum age of 18 years, diagnosis of CHD, and enrollment in LLT. The only exclusion criterion was the absence of written informed consent. The ethics committee of the Medical Association of Saxony-Anhalt and the local ethics committees of the participating clinics approved this study (ClinicalTrials.gov Identifier: NCT02749279). 


\subsection{Patient Data}

A central database (online-CRF) recorded all relevant baseline parameters, which included indication for rehabilitation, LLT and other drug treatments, all comorbidities, age, sex, BMI, and standard laboratory parameters (e.g., total, LDL, and HDL cholesterol and triglycerides). Moreover, the database contained information on LLT at the beginning of $\mathrm{CR}$, at discharge, as well as on the advice given to general practitioners regarding how LLT should be managed after discharge.

Diabetes was defined as previously diagnosed (under treatment) or newly diagnosed disease during $\mathrm{CR}$ according to current guidelines (i.e., $\mathrm{HbA} 1 \mathrm{c}>6.5 \%$ or $48 \mathrm{mmol} / \mathrm{mol}$, fasting glucose $>7 \mathrm{mmol} / \mathrm{L}$, random plasma glucose $>11.0 \mathrm{mmol} / \mathrm{L}$ or $2 \mathrm{~h}$ plasma glucose $>11.0 \mathrm{mmol} / \mathrm{L}$ in an oral glucose tolerance test) [1]. The study included both type 1 diabetes (approximately 2\%) and type 2 diabetes (approximately 98\%) patients.

\subsection{Cardiac Rehabilitation}

The cardiac rehabilitation for patients with CHD included diagnostic procedures such as cycle ergometry, echocardiography, and ECG. Patients who were unable to perform cycle ergometry performed a 6 min walking test instead. A sports and rehabilitation program was set up for each patient taking into account physical fitness, severity of primary disease, comorbidities, and other confounding parameters. Patients in good clinical condition participated in heart rate-monitored cycle ergometry training for $30 \mathrm{~min}$. In addition, these patients participated in Nordic walking, medical training therapy, aquatic therapy, and intensive gymnastics or exercise. Patients who were less physically fit participated in group exercises, chair exercises, walking exercises, and personal training sessions. Data on patient assignment according to physical fitness levels were not collected. All patients, irrespective of their physical fitness, attended seminars and lectures over the course of the 3 week rehabilitation program, and received their medication from nurses during their stay.

\subsection{Follow-Up}

During follow-up, patients were contacted by mail 3 and 12 months after discharge to inquire about drug therapy (in particular concerning LLT) and rehospitalization, especially in connection with atherosclerotic diseases, such as recurrent acute coronary syndromes (ACS). Additional information was collected on the rationale and the responsible party for changes in medication. In addition, data on total, LDL, and HDL cholesterol as well as triglyceride levels were collected during follow-up. Patients who failed to return the questionnaires were contacted via telephone to conduct an interview with the patient or his/her relatives. Occasionally, the patient's physician was contacted as well. Civil registration offices were contacted if this information could not be retrieved from these sources, and information was requested about current addresses or date of death. This study employed a monitoring protocol that was developed by the Coordination Center for Clinical Studies, Martin Luther-University Halle Wittenberg, Germany (KKS Halle).

\subsection{Statistical Analysis}

Continuous variables were described as mean and standard deviation, skewed variables as median and $25 \%$ and $75 \%$ quartiles. Categorical variables were documented as a percentage. A $t$-test was used to compare metric, normally distributed variables. For skewed variables, the Mann-Whitney U-test was employed. The chi-squared test was used for normally distributed, categorical variables. Odds ratios were calculated via chi-square test from contingency tables. A one-way ANOVA was employed for comparisons between diabetic and nondiabetic patients over time, and for evaluating the time course of lipid levels. A $t$-test was performed for post hoc pairwise comparison. Results were deemed significant for $p$-values lower than 0.05 . Statistical analysis was performed with SPSS Statistics (IBM ${ }^{\circledR}$ SPSS $^{\circledR}$ Statistics 25, Chicago, IL, USA). 


\section{Results}

\subsection{Patient Characteristics}

Patient characteristics are presented in Table 1 . The registry included $76.1 \%$ male and $23.9 \%$ female patients. Main diagnoses were NSTEMI (31.8\%), STEMI $(29.6 \%)$, and CABG surgery $(26.4 \%)$. In 369 patients $(33.9 \%)$, diabetes mellitus was diagnosed. On average, diabetic patients were 3 years older than nondiabetic patients $(65.5 \pm 9.0$ years vs. $62.2 \pm 10.9$ years, $p<0.001$ ). In addition, diabetic patients showed a higher BMI $\left(30.2 \pm 5.2 \mathrm{~kg} / \mathrm{m}^{2}\right.$ vs. $\left.27.8 \pm 4.2 \mathrm{~kg} / \mathrm{m}^{2}\right)$, larger waist circumference $(107.8 \pm 12.9 \mathrm{~cm}$ vs. $101.2 \pm 11.6 \mathrm{~cm})$, higher systolic blood pressure $(135.6 \pm 21.9 \mathrm{mmHg}$ vs. $132 \pm 19.9 \mathrm{mmHg}$, $p<0.001)$, and higher heart rate $(75.8 \pm 11.6 \mathrm{bpm}$ vs. $71.9 \pm 12.4 \mathrm{bpm}, p<0.001)$ than nondiabetic patients. Furthermore, renal function was reduced in diabetic patients (creatinine: $1.1 \pm 0.5 \mathrm{mg} / \mathrm{dL}$ vs. $1.0 \pm 0.3 \mathrm{mg} / \mathrm{dL}$; eGFR: $74.0 \pm 22.2 \mathrm{~mL} / \mathrm{min}$ vs. $78.8 \pm 18.0 \mathrm{~mL} / \mathrm{min}$, $p<0.001$ for both), and hemoglobin levels were lower $(12.9 \pm 1.9 \mathrm{~g} / \mathrm{dL}$ vs. $13.5 \pm 3.7 \mathrm{~g} / \mathrm{dL}$, $p<0.001)$. Information on $\mathrm{HbA1c}$, which was available for only 243 diabetics $(65.9 \%)$, yielded a value of $6.7 \pm 0.9 \%$ (or $50 \pm 10 \mathrm{mmol} / \mathrm{mol}$ ). Diabetic patients showed three-vessel CHD significantly more often than patients without diabetes $(p<0.001$; Table 1$)$.

Table 1. Overview of patient characteristics at the end of CR.

\begin{tabular}{|c|c|c|c|c|c|c|c|c|c|c|c|c|c|c|}
\hline \multirow{2}{*}{ Characteristic } & & \multicolumn{4}{|c|}{ All Patients } & \multicolumn{4}{|c|}{ without Diabetes } & \multicolumn{4}{|c|}{ with Diabetes } & \multirow{2}{*}{$p$-Value } \\
\hline & & $\mathbf{N}$ & $\%$ & $\bar{X}$ & SD & $\mathbf{N}$ & $\%$ & $\bar{X}$ & SD & $\mathbf{N}$ & $\%$ & $\bar{X}$ & SD & \\
\hline Age (years) & & 1087 & 100 & 63.4 & 10.4 & 716 & 65.9 & 62.2 & 10.9 & 369 & 33.9 & 65.6 & 9.0 & 0.000 \\
\hline Body Weight (kg) & & 1083 & 100 & 84.9 & 16.5 & 714 & 65.9 & 83.1 & 15.5 & 367 & 33.9 & 88.4 & 17.9 & 0.000 \\
\hline $\operatorname{BMI}\left(\mathrm{kg} / \mathrm{m}^{2}\right)$ & & 1082 & 100 & 28.6 & 4.7 & 711 & 65.7 & 27.8 & 4.2 & 369 & 34.1 & 30.2 & 5.2 & 0.000 \\
\hline Waist circumference $(\mathrm{cm})$ & & 904 & 100 & 103.5 & 12.5 & 588 & 65.0 & 101.2 & 11.6 & 315 & 34.8 & 107.8 & 12.9 & 0.000 \\
\hline Systole (mmHg) & & 1086 & 100 & 133.2 & 20.6 & 715 & 65.8 & 132.0 & 19.9 & 369 & 34.0 & 135.6 & 21.9 & 0.023 \\
\hline Diastole (mmHg) & & 1086 & 100 & 78.0 & 11.4 & 715 & 65.8 & 78.2 & 11.3 & 369 & 34.0 & 77.7 & 11.6 & 0.556 \\
\hline Heart rate (bpm) & & 1085 & 100 & 73.2 & 12.3 & 714 & 65.8 & 71.9 & 12.4 & 369 & 34.0 & 75.8 & 11.6 & 0.000 \\
\hline Creatine $[\mathrm{mg} / \mathrm{dL}]$ & & 1084 & 100 & 1.0 & 0.4 & 713 & 65.8 & 1.0 & 0.3 & 369 & 34.0 & 1.1 & 0.5 & 0.000 \\
\hline GFR $[\mathrm{mL} / \mathrm{min}]$ & & 1083 & 100 & 77.1 & 19.7 & 712 & 65.7 & 78.7 & 18.0 & 369 & 34.1 & 74.0 & 22.2 & 0.000 \\
\hline Hemoglobin [g/dL] & & 1075 & 100 & 13.2 & 5.6 & 709 & 66.0 & 13.5 & 3.7 & 366 & 34.0 & 12.6 & 1.9 & 0.000 \\
\hline HBA1c [\%] & & & & & & & & & & 243 & & 6.7 & 0.9 & $\mathrm{n} / \mathrm{a}$ \\
\hline \multirow{2}{*}{ Sex } & Male & 826 & 76.1 & & & 557 & 77.8 & & & 269 & 72.9 & & & \multirow{9}{*}{0.073} \\
\hline & Female & 259 & 23.9 & & & 159 & 22.2 & & & 100 & 27.1 & & & \\
\hline \multirow{6}{*}{ Indication for admission } & NSTEMI & 345 & 31.8 & & & 231 & 32.3 & & & 114 & 30.9 & & & \\
\hline & STEMI & 321 & 29.6 & & & 239 & 33.4 & & & 82 & 22.2 & & & \\
\hline & CABG & 286 & 26.4 & & & 165 & 23.0 & & & 121 & 32.8 & & & \\
\hline & $\mathrm{PCI} /$ Stent & 61 & 5.6 & & & 35 & 4.9 & & & 26 & 7.0 & & & \\
\hline & Valve & 37 & 3.4 & & & 25 & 3.5 & & & 12 & 3.3 & & & \\
\hline & Others & 35 & 3.2 & & & 21 & 2.9 & & & 14 & 3.8 & & & \\
\hline \multirow{3}{*}{ Affected blood vessels } & 1-CAD & 289 & 25.0 & & & 203 & 28.6 & & & 65 & 17.9 & & & \\
\hline & 2-CAD & 274 & 25.5 & & & 200 & 28.1 & & & 74 & 20.4 & & & \multirow[t]{2}{*}{0.000} \\
\hline & 3-CAD & 532 & 49.5 & & & 308 & 43.3 & & & 224 & 61.7 & & & \\
\hline
\end{tabular}

${ }^{\mathrm{a}}$ statistical difference between patients with diabetes and without. Statistical significance is indicated in bold. BMI, body mass index; CABG, coronary artery bypass surgery; CAD, oronary artery disease; GFR, glomerular filtration rate; HbA1c, glycated hemoglobin; NSTEMI, non-ST elevation myocardial infarction; PCI, percutaneous coronary intervention; SD, standard deviation; STEMI, ST elevation myocardial infarction; $\bar{X}$, sample mean.

\subsection{Low LDL Levels among Diabetic and Nondiabetic Patients}

Recent guidelines recommend LDL cholesterol levels <55 mg/dL for LLT [6]. Hence, we evaluated the impact of diabetes mellitus on this particular patient subgroup. The data from this registry showed that patients with diabetes mellitus were more likely to reach this goal by the time of admission to CR than nondiabetic patients (OR 1.9; 95\% CI 1.3 to 2.9).

In addition, the group with LDL cholesterol $<55 \mathrm{mg} / \mathrm{dL}$ contained significantly more diabetic than nondiabetic patients (chi-squared test, $p=0.001$ ) (Figure 1 ). The same trend was observed at the time of discharge, but the analysis failed to reach statistical significance (chi-squared test, $p=0.068$ ). At 3 months after $C R$, diabetes patients were again more likely to have LDL cholesterol levels $<55 \mathrm{mg} / \mathrm{dL}$ than those without diabetes (OR 1.9; 95\% CI 1.2 to 2.9). Once again, there were significantly more diabetic patients than nondiabetic patients 
in the group with LDL cholesterol $<55 \mathrm{mg} / \mathrm{dL}$ (chi-squared test, $p=0.006$ ) (Figure 1). After 12 months of follow-up, however, there was no difference between diabetic and nondiabetic patients (chi-squared test, $p=0.413$ ).

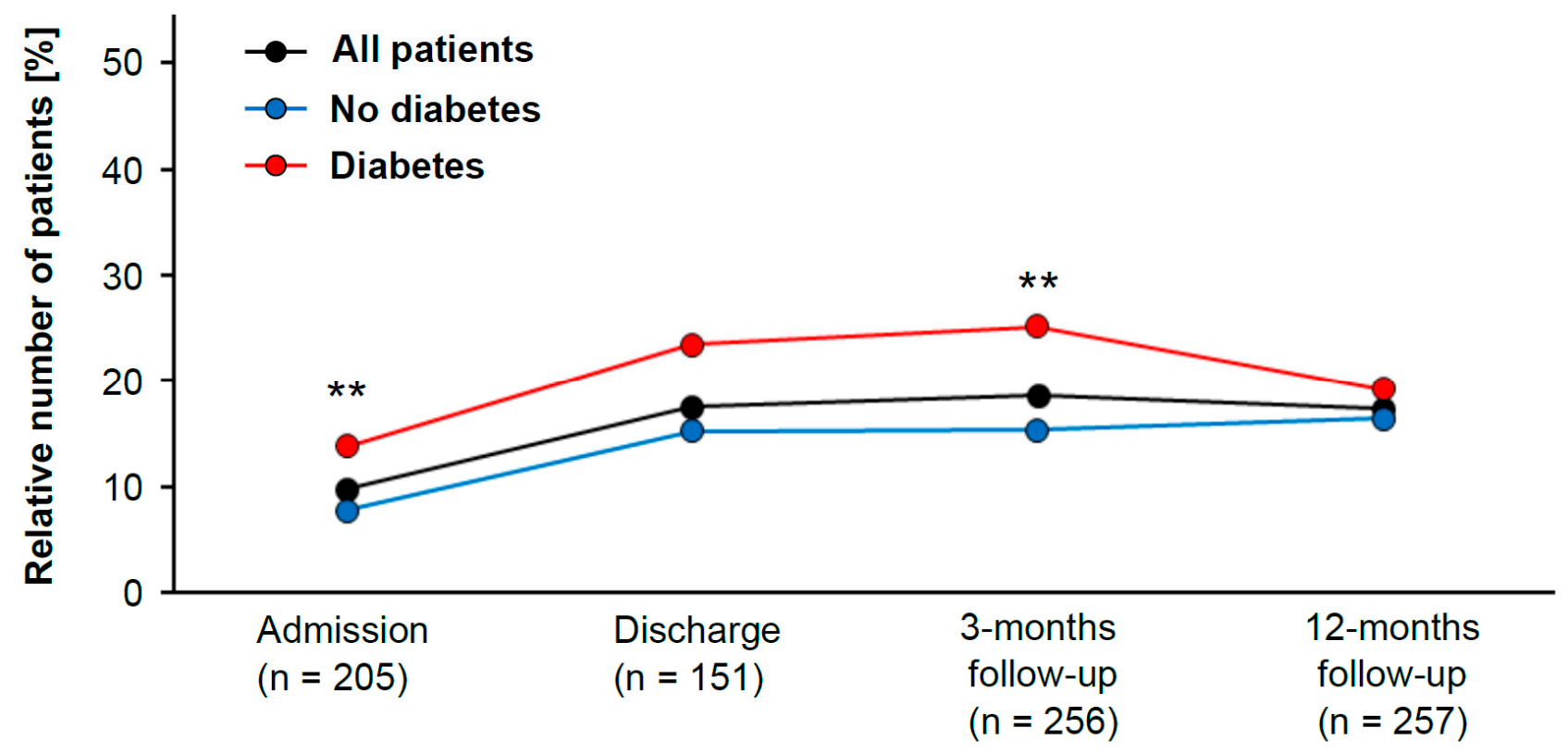

Figure 1. Patient population with low LDL cholesterol levels (classified as $<55 \mathrm{mg} / \mathrm{dL}$ ) during study period (in black). Patients are subdivided into diabetic (red) and nondiabetic (blue) patients. The statistically significant difference between diabetic and nondiabetic patients was evaluated with the Pearson's chi-squared test (** indicates $p$-value $<0.01)$.

\subsection{Lipid Levels of the Patients during $C R$}

A time course of lipid levels is presented in Figure 2. Statistical analysis showed a significant reduction in total cholesterol: $156.0 \pm 37.5 \mathrm{mg} / \mathrm{dL}$ at discharge to $149.6 \pm 42.5 \mathrm{mg} / \mathrm{dL}$ at 3 months after CR $(p=0.002)$. This lower level was confirmed at the end of follow-up at 12 months $(146.2 \pm 37.3 \mathrm{mg} / \mathrm{dL} ; p<0.001)$. Similarly, LDL cholesterol dropped within 3 months from $91.4 \pm 30.8 \mathrm{mg} / \mathrm{dL}$ at discharge to $81.2 \pm 30.2 \mathrm{mg} / \mathrm{dL}$ at 3 months after $\mathrm{CR}(p<0.001)$, remaining at this level until the end of the follow-up $(79.3 \pm 27.2 \mathrm{mg} / \mathrm{dL}$; $p<0.001)$. These results did not differ significantly between patients with and without diabetes mellitus (Figure 2A,B). In contrast, HDL cholesterol increased from $45.0 \pm 13.8 \mathrm{mg} / \mathrm{dL}$ at discharge to $49.5 \pm 14.8 \mathrm{mg} / \mathrm{dL}$ at 3 months $(p<0.001)$, remaining at this level until 12 months of follow-up $(49.5 \pm 14.4 \mathrm{mg} / \mathrm{dL} ; p<0.001)$. Moreover, HDL cholesterol levels differed significantly between patients with and without diabetes mellitus $(p<0.01$; Figure 2C). For triglycerides, the differences between the two patient groups were significant ( $p=0.027$ ) (Figure 2D). However, the average triglyceride levels for all patients in this registry were $137.5 \pm 77.0 \mathrm{mg} / \mathrm{dL}$ at the beginning of CR and remained virtually unchanged at $135.5 \pm 78.9 \mathrm{mg} / \mathrm{dL}$ on average after 12 months of follow-up. 
A

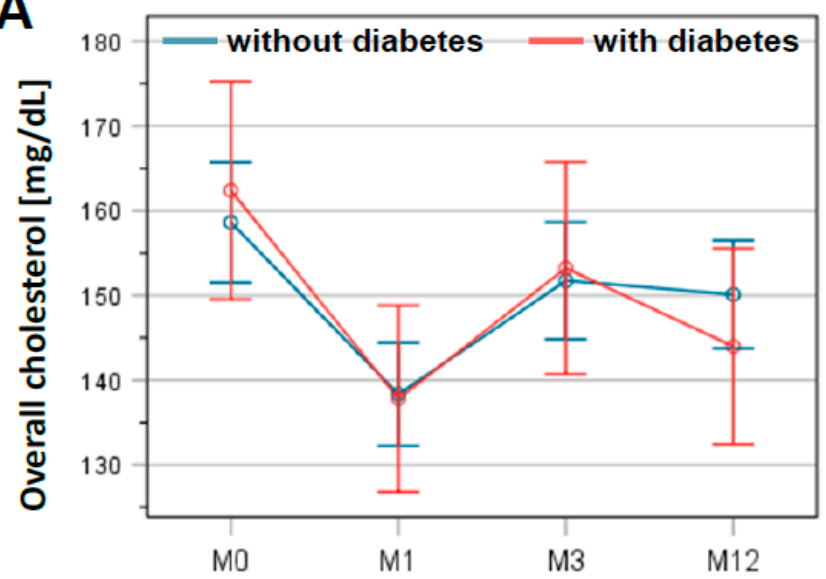

C

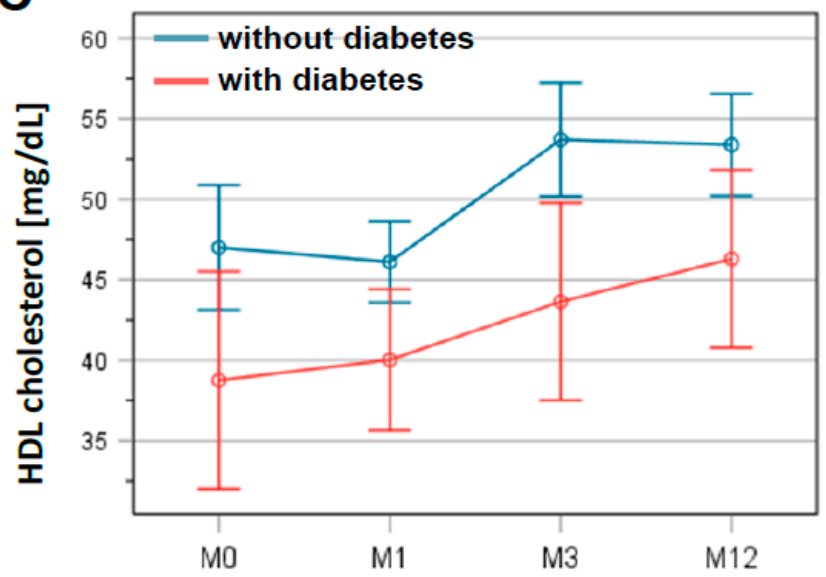

B

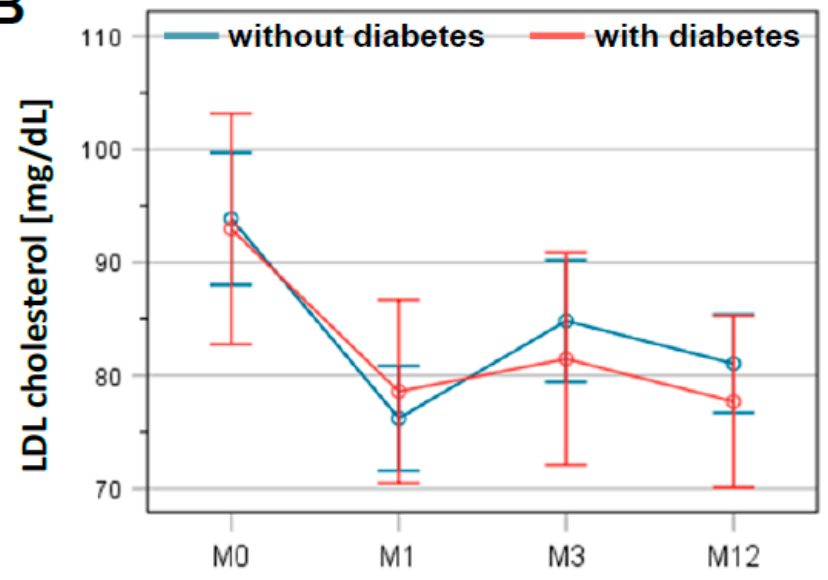

D

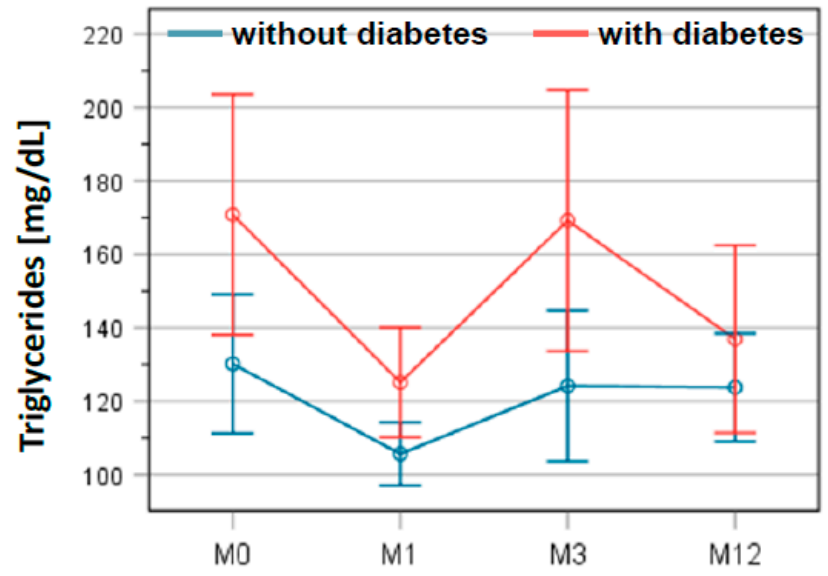

Figure 2. Changes in lipid levels in patients with and without diabetes mellitus during study period. Levels of overall cholesterol (A), LDL cholesterol (B), HDL cholesterol (C), and triglycerides (D) are presented at the beginning (M0) and the end of the cardiac rehabilitation (M1) as well as 3 months (M3) and 12 months (M12) after discharge. The graphs show the mean and the error bars represent the $95 \%$ confidence interval. Patients with diabetes are indicated in red, patients without in blue.

\subsection{LLT during Study Period}

This registry also assessed the differences in LLT between diabetic and nondiabetic patients. There was no significant difference for statins (Figure 3A) in the two groups. The same was observed for ezetimibe, which is the most often used alternative to statins (Figure 3B). 
A

non-diabetics

diabetics

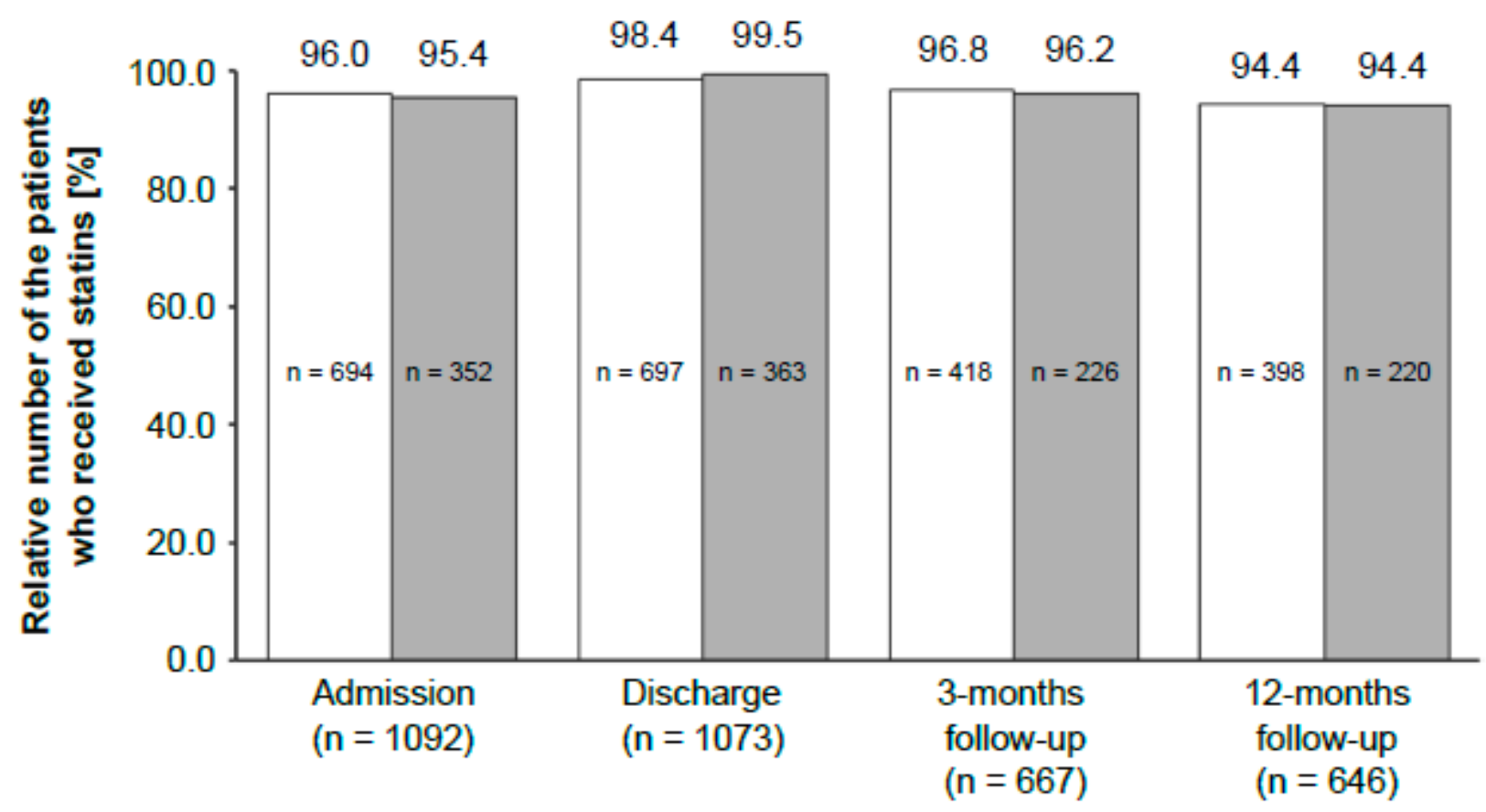

B

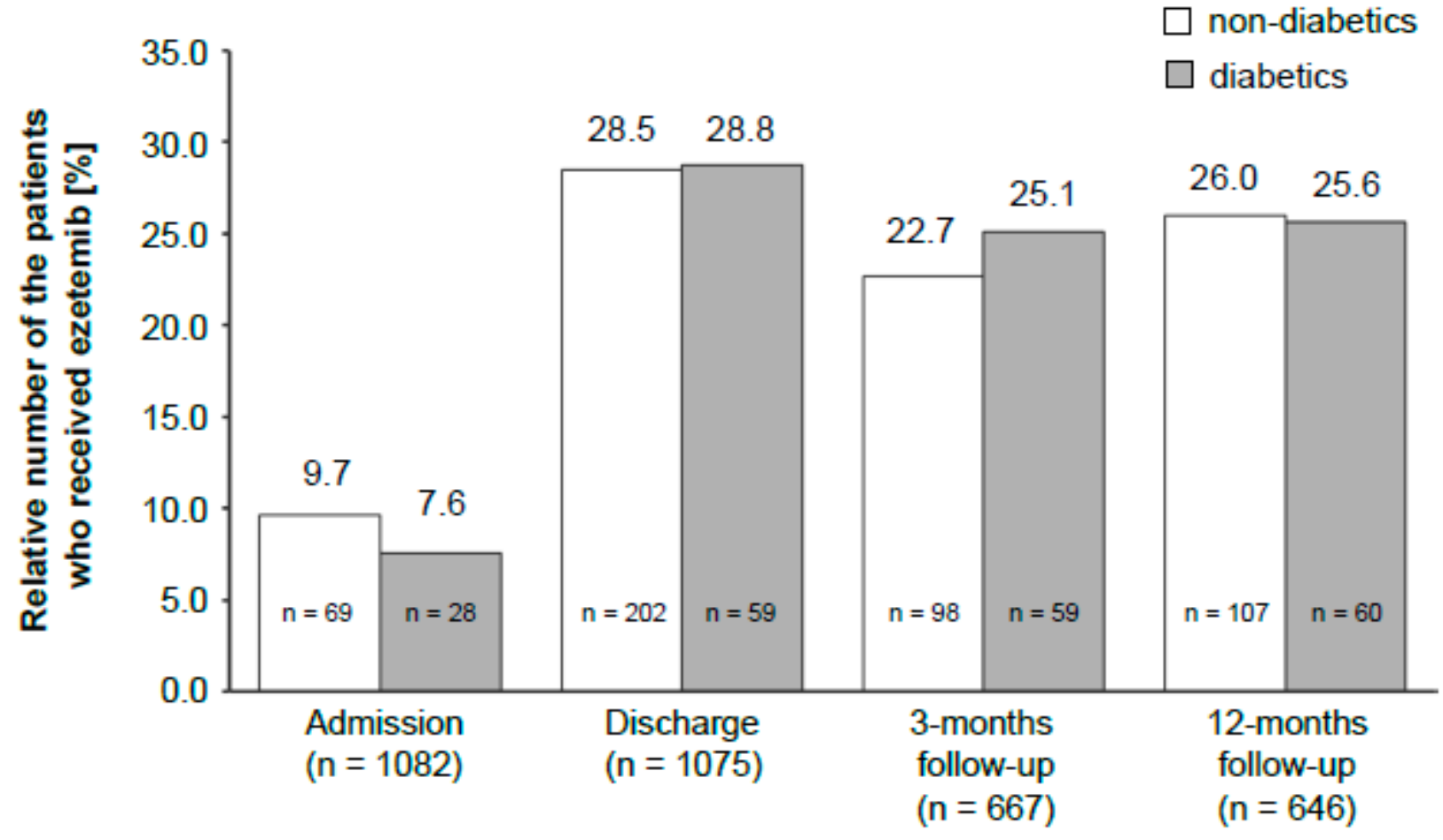

Figure 3. Distribution of LLT drugs in the patient population during the study period. The bar graph shows a comparison of the administration of statins (A) and ezetemib (B) among diabetic and nondiabetic patients at different time points. The number above the bar graph indicates the percentage of diabetics or nondiabetics, respectively, who received the drug. The number in the bar graph presents the total number of patients. The number on the $x$-axis shows the total amount of patients in this particular study period. 


\subsection{Drug Therapy}

Besides lipid-lowering drugs, concomitant medication was analyzed during CR (see Table 2). The analysis did not show any significant difference between diabetic and nondiabetic patients for oral anticoagulants or platelets inhibitors, with Prasugrel being the only exception: Prasugrel was used less frequently by diabetic than nondiabetic patients $(14.8 \%$ vs. $27.9 \%, p<0.001)$. Regarding antihypertensive drugs, diabetic patients used significantly more diuretics $(56.4 \%$ vs. $38.1 \%, p<0.001)$, angiotensin II receptor blockers (ARB; $37.5 \%$ vs. $28.6 \%, p=0.005$ ), and calcium channel blockers (CCB; $30.4 \%$ vs. $18.2 \%$, $p<0.001)$ than patients without diabetes. In contrast, diabetic patients were medicated less frequently with angiotensin-converting enzyme (ACE) inhibitors (57.6\% vs. $66.1 \%)$ $(p=0.007)$.

Table 2. Comparison of diabetic vs. nondiabetic patients at baseline during non-LLT drug therapy.

\begin{tabular}{|c|c|c|c|c|c|c|c|c|}
\hline \multirow{2}{*}{ Characteristic } & & \multicolumn{2}{|c|}{ All Patients } & \multicolumn{2}{|c|}{ without Diabetes } & \multicolumn{2}{|c|}{ with Diabetes } & \multirow{2}{*}{$p$-Value ${ }^{a}$} \\
\hline & & $\mathbf{N}$ & $\%$ & $\mathbf{N}$ & $\%$ & $\mathbf{N}$ & $\%$ & \\
\hline \multirow{4}{*}{ Platelet inhibitors } & ASA & 1031 & 97.6 & 680 & 97.8 & 351 & 97.2 & 0.535 \\
\hline & Clopidogrel & 251 & 25.8 & 151 & 24.0 & 100 & 29.2 & 0.080 \\
\hline & Prasugrel & 224 & 23.3 & 174 & 27.9 & 50 & 14.8 & 0.000 \\
\hline & Ticagrelor & 342 & 34.4 & 232 & 35.9 & 110 & 31.6 & 0.178 \\
\hline \multirow{5}{*}{ Oral anticoagulants } & Vitamin $\mathrm{K}$ antagonist & 64 & 33.7 & 39 & 32.2 & 25 & 36.2 & 0.575 \\
\hline & Dabigatran & 52 & 28.0 & 28 & 23.9 & 24 & 34.8 & 0.111 \\
\hline & Rivaroxaban & 5 & 2.8 & 2 & 1.8 & 3 & 4.5 & 0.363 \\
\hline & Edoxaban & 6 & 3.4 & 6 & 5.4 & 0 & 0.0 & 0.085 \\
\hline & Apixaban & 25 & 13.7 & 21 & 18.3 & 4 & 6.0 & 0.020 \\
\hline \multirow{7}{*}{ Anti-hypertensives } & Diuretics & 446 & 44.5 & 249 & 38.1 & 197 & 56.4 & 0.000 \\
\hline & ACE inhibitors & 654 & 63.2 & 449 & 66.1 & 205 & 57.6 & 0.007 \\
\hline & $\mathrm{ARB}$ & 307 & 31.7 & 180 & 28.6 & 127 & 37.5 & 0.005 \\
\hline & Renin inhibitors & 3 & 0.3 & 3 & 0.5 & 0 & 0.0 & 0.556 \\
\hline & $\mathrm{CCB}$ & 221 & 22.5 & 117 & 18.2 & 104 & 30.4 & 0.000 \\
\hline & Beta blocker & 959 & 90.4 & 632 & 90.5 & 327 & 90.1 & 0.809 \\
\hline & MRAs & 121 & 12.5 & 84 & 13.4 & 37 & 10.9 & 0.281 \\
\hline
\end{tabular}

${ }^{a}$ statistical difference between patients with diabetes and without. Statistical significance is indicated in bold. ASA, acetylsalicylic acid; $\mathrm{ACE}$, angiotensin-converting enzyme; ARB, angiotensin II receptor blocker; CCB, calcium channel blocker; MRA, mineralocorticoid receptor antagonist.

\subsection{Antidiabetic Drugs}

In Table 3, antidiabetic medication use is presented. Metformin was the most commonly used antidiabetic drug in $48.0 \%$ of the patients at admission and remained the preferred drug through the 12-month follow-up period (51.7\% of the patients). DDP-4 inhibitors were also used frequently according to the registry data $(26.8 \%$ at admission and $26.5 \%$ at the end of the study). The use of insulin declined from $33.3 \%$ at admission to $26.9 \%$ at the end of the documented follow-up. Other antidiabetic drugs, such as sulfonylureas, GLP1 agonists, and meglitinides, were used in less than $5 \%$ of the patients at any time. Of note, SGLT2 inhibitor use increased from 3.3\% at admission to $7.3 \%$ during the 12 -month follow-up period.

Table 3. Antidiabetic drugs among patients with diabetes mellitus during study period.

\begin{tabular}{|c|c|c|c|c|c|c|c|c|}
\hline \multirow{3}{*}{ Antidiabetics } & \multicolumn{2}{|c|}{ Admission } & \multicolumn{2}{|c|}{ Demission } & \multicolumn{2}{|c|}{ 3-Months Follow-Up } & \multicolumn{2}{|c|}{ 12-Months Follow-Up } \\
\hline & \multicolumn{2}{|c|}{$n=369$} & \multicolumn{2}{|c|}{$\mathrm{n}=364$} & \multicolumn{2}{|c|}{$\mathrm{n}=\mathbf{2 3 5}$} & \multicolumn{2}{|c|}{$\mathrm{n}=234$} \\
\hline & $\mathbf{N}$ & $\%$ & $\mathbf{N}$ & $\%$ & $\mathbf{N}$ & $\%$ & $\mathbf{N}$ & $\%$ \\
\hline Any antidiabetics & 272 & 73.7 & 265 & 72.8 & 165 & 70.2 & 164 & 70.1 \\
\hline Metformin & 177 & 48.0 & 194 & 53.3 & 126 & 53.6 & 121 & 51.7 \\
\hline Sulfonylureas & 18 & 4.9 & 6 & 1.6 & 6 & 2.6 & 8 & 3.4 \\
\hline DPP-4 inhibitors & 99 & 26.8 & 103 & 28.3 & 57 & 24.3 & 62 & 26.5 \\
\hline GLP1 agonists & 7 & 1.9 & 9 & 2.5 & 3 & 1.3 & 7 & 3.0 \\
\hline SGTL2 inhibitors & 12 & 3.3 & 21 & 5.8 & 16 & 6.8 & 17 & 7.3 \\
\hline Meglitinides & 2 & 0.5 & 2 & 0.5 & 3 & 1.3 & 2 & 0.9 \\
\hline Insulin & 123 & 33.3 & 108 & 29.7 & 56 & 23.8 & 63 & 26.9 \\
\hline
\end{tabular}




\section{Discussion}

This prospective, multicenter registry study investigated the effect of LLT on CHD patients in a CR setting in order to assess the benefit of this therapy for diabetics and nondiabetics. The study showed a significant reduction in LDL cholesterol levels for all patients, but the improvement was greater for diabetic patients.

The multicenter LLT-R registry provided a representative cross-section of CHD patients and the treatment situation during and after CR in Germany. The registry data are based on only one exclusion criterion (i.e., the lack of informed consent) and the overall characteristics of the patient cohort, such as an average age of 63 years and less than $25 \%$ females [18,24-27]. Multimodal rehabilitation in Germany results in several improvements during start and end of rehabilitation, including decreases in systolic blood pressure, heart rate, and waist circumference, but not in BMI $[18,24]$. These findings are in excellent agreement with our observation regarding the unchanged body weight during follow-up after discharge from CR. Furthermore, effective CR could also account for the observed decline in insulin therapy during the course of LLT in the registry.

In agreement with the literature, this registry showed that total and LDL cholesterol levels changed within the first 3 months after CR, and then remained at that level, irrespective of prevalent diabetes mellitus. By contrast, the HDL levels in nondiabetic patients remained constant 3 months after CR, whereas HDL levels in diabetic patients continued to increase in the same period. In addition, our analysis indicated a faster decline in LDL cholesterol levels below $55 \mathrm{mg} / \mathrm{dL}$ in diabetes mellitus patients than in patients without diabetes. It should be stated, however, that the few measurement time points in the follow-up period provide only a low resolution of the kinetics of these adjustments. In any case, these observations suggest that both diabetics and nondiabetics benefit from LLT regarding LDL cholesterol levels. In contrast, it is unclear why diabetic patients show a more pronounced increase in HDL cholesterol levels than nondiabetic patients, and thus seemingly benefit even more from LLT. This notion is supported by an earlier study that found a greater risk reduction for major coronary events in diabetic $(42 \%)$ than in nondiabetic patients (32\%) [27]. One explanation could be that antidiabetic drugs influence cholesterol levels in this setting. Another explanation could be differences in metabolic and physiological process between diabetics and nondiabetic patients. A better understanding has implications for the recruitment of diabetic patients to CR, and the role of antidiabetic medication within LLT. Further studies are required to elucidate the biological reason for the differing outcome among both patient groups.

In the cohort of this CR registry, $33.9 \%$ of patients had received a diagnosis of diabetes mellitus (Table 1), whereas the overall rate of diabetic patients among all cardiac events in the German population varies between only $10 \%$ and $16 \%$ [29]. The overrepresentation of patients with diabetes mellitus in the $\mathrm{CR}$ registry cohort is in agreement with the role of diabetes mellitus as a major risk factor for development of CHD [1], hence improving quality of life and prognosis in CHD patients. This is particularly relevant for CHD patients with diabetes mellitus who tend to have increased lipid levels the higher number of high risk patients, such as elderly people who have suffered myocardial infarction and who are admitted more frequently to $C R$ than younger diabetic patients with less severe cardiac events. Nonetheless, this discrepancy between the general population and the registry is a coincidental observation that requires thorough statistical assessment. In any case, the findings presented here have implications for CR patients or patients with recurrent cardiac events. This is particularly important in light of the continuously increasing magnitude of this patient group due to the growing number of multimorbid and older patients.

There are several limitations of this registry. First of all, it is difficult to interpret the data set due to the observational and nonrandomized design of the patient cohort. Changing the design of this study by introducing a control group is almost impossible as every patient in Germany has the litigable right to participate in CR after ACS or CABG [18,24-27]. Nonetheless, this study aimed for the highest possible data quality. The Coordination Center for Clinical Studies, Martin Luther-University Halle Wittenberg, 
Germany (KKS Halle), enrolled patients consecutively on a prospective basis in order to provide adequate monitoring and to record all relevant patient information.

In addition, there may be potential incoherencies in LLT medication in this registry. In general, the study showed no differences in treatment of diabetic and nondiabetic patients during LTT. Nonetheless, patients received different drugs during the course of CR in order to address clinical needs, such as duration and severity of disease as well as comorbidities. Consequently, these changes in medication confound the association between treatment and outcome, thus introducing channeling or allocation biases. Unfortunately, compliance was not assessed during the $\mathrm{CR}$, but rehabilitation centers and patients enrolled in prospective studies are more likely to adhere to guideline-oriented therapy than patients outside of such centers or studies. Since nurses provided patients with their medication during the three weeks of CR, it is reasonable to assume that the overwhelming majority of patients adhered to drug therapy.

Moreover, different types of diabetes mellitus could not be addressed separately in this registry as data on the specific types were limited and inconclusive. This would have been an ideal scenario but the authors are aware of the fact that ideal scenarios do not exist in the CR setting, and hence this limitation reflects the reality of the rehabilitation setting. Similarly, this study did not collect data on the fitness level of the patients and their assignment to $\mathrm{CR}$ measures. Therefore, it cannot be excluded that allocation of patients to different exercise regimes within the $C R$ framework may have influenced the response to LLT. Lastly, a follow-up period of 12 months is rather short for monitoring lifelong chronic diseases. Hence, a longer follow-up period might have shown further differences between patients with and without diabetes mellitus.

\section{Conclusions}

This study demonstrated that implementation of LLT in context of CR is able to reduce LDL cholesterol within a short time period of 3 months in patients with CHD. The outcome of this prospective study showed that concomitant diabetes mellitus in addition to antidiabetic medication did not impair the efficacy of LLT during CR. On the contrary, patients with diabetes seemed to benefit most from LLT during CR, as they reached LDL treatment goals significantly better than patients without diabetes mellitus during CR.

Author Contributions: T.W.: validation, conceptualization, methodology, writing original draft; B.S.: study conception, data curation, investigation, writing-review and editing; H.V.: data curation, investigation, writing-review and editing; C.B.: data curation, investigation; V.H.: data curation, investigation; K.E.: data curation, investigation; M.G.: data curation, investigation; M.R.: Conceptualization, methodology, data curation; A.S.: Conceptualization, methodology, data curation, investigation, writing-review and editing. All authors have read and agreed to the published version of the manuscript.

Funding: This research received no external funding.

Institutional Review Board Statement: The ethics committee of the Medical Association of SaxonyAnhalt and the local ethics committees of the participating clinics approved this study (ClinicalTrials.gov Identifier: NCT02749279). All patients signed an informed consent before study entry.

Informed Consent Statement: All authors agree to publication.

Data Availability Statement: All source data are available upon request.

Conflicts of Interest: The authors declare no conflict of interest.

\section{References}

1. Cosentino, F.; Grant, P.J.; Aboyans, V.; Bailey, C.J.; Ceriello, A.; Delgado, V.; Federici, M.; Filippatos, G.; Grobbee, D.E.; Hansen, T.B.; et al. 2019 ESC Guidelines on diabetes, pre-diabetes, and cardiovascular diseases developed in collaboration with the EASD. Eur. Heart J. 2020, 41, 255-323. [CrossRef] [PubMed]

2. Burggraaf, B.; Castro Cabezas, M. Interventions in type 2 diabetes mellitus and cardiovascular mortality-An overview of clinical trials. Eur. J. Intern. Med. 2017, 42, 1-15. [CrossRef] [PubMed] 
3. $\quad$ Reiner, Z.; De Backer, G.; Fras, Z.; Kotseva, K.; Tokgozoglu, L.; Wood, D.; De Bacquer, D.; Investigators, E. Lipid lowering drug therapy in patients with coronary heart disease from 24 European countries-Findings from the EUROASPIRE IV survey. Atherosclerosis 2016, 246, 243-250. [CrossRef]

4. Mach, F.; Baigent, C.; Catapano, A.L.; Koskinas, K.C.; Casula, M.; Badimon, L.; Chapman, M.J.; De Backer, G.G.; Delgado, V.; Ference, B.A.; et al. 2019 ESC/EAS guidelines for the management of dyslipidaemias: Lipid modification to reduce cardiovascular risk. Eur. Heart J. 2020, 41, 111-188. [CrossRef] [PubMed]

5. Piepoli, M.F.; Hoes, A.W.; Agewall, S.; Albus, C.; Brotons, C.; Catapano, A.L.; Cooney, M.T.; Corra, U.; Cosyns, B.; Deaton, C.; et al. 2016 European guidelines on cardiovascular disease prevention in clinical practice: The sixth joint task force of the european society of cardiology and other societies on cardiovascular disease prevention in clinical practice (constituted by representatives of 10 societies and by invited experts) developed with the special contribution of the european association for cardiovascular prevention \& rehabilitation (EACPR). Eur. Heart J. 2016, 37, 2315-2381. [CrossRef]

6. Catapano, A.L.; Graham, I.; De Backer, G.; Wiklund, O.; Chapman, M.J.; Drexel, H.; Hoes, A.W.; Jennings, C.S.; Landmesser, U.; Pedersen, T.R.; et al. 2016 ESC/EAS guidelines for the management of dyslipidaemias. Eur. Heart J. 2016, 37, 2999-3058. [CrossRef]

7. Laks, T.; Keba, E.; Leiner, M.; Merilind, E.; Petersen, M.; Reinmets, S.; Vali, S.; Soot, T.; Otter, K. Achieving lipid goals with rosuvastatin compared with simvastatin in high risk patients in real clinical practice: A randomized, open-label, parallel-group, multi-center study: The DISCOVERY-Beta study. Vasc. Health Risk Manag. 2008, 4, 1407-1416. [CrossRef]

8. Schwartz, G.G.; Olsson, A.G.; Ezekowitz, M.D.; Ganz, P.; Oliver, M.F.; Waters, D.; Zeiher, A.; Chaitman, B.R.; Leslie, S.; Stern, T.; et al. Effects of atorvastatin on early recurrent ischemic events in acute coronary syndromes: The MIRACL study: A randomized controlled trial. JAMA 2001, 285, 1711-1718. [CrossRef] [PubMed]

9. Sever, P.S.; Poulter, N.R.; Dahlof, B.; Wedel, H.; Collins, R.; Beevers, G.; Caulfield, M.; Kjeldsen, S.E.; Kristinsson, A.; McInnes, G.T.; et al. Reduction in cardiovascular events with atorvastatin in 2532 patients with type 2 diabetes: Anglo-scandinavian cardiac outcomes trial-lipid-lowering arm (ASCOT-LLA). Diabetes Care 2005, 28, 1151-1157. [CrossRef]

10. Ramkumar, S.; Raghunath, A.; Raghunath, S. Statin therapy: Review of safety and potential side effects. Acta Cardiol. Sin. 2016, 32, 631-639. [CrossRef]

11. Tomaszewski, M.; Stepien, K.M.; Tomaszewska, J.; Czuczwar, S.J. Statin-induced myopathies. Pharmacol. Rep. 2011, 63, 859-866. [CrossRef]

12. Leutner, M.; Matzhold, C.; Bellach, L.; Deischinger, C.; Harreiter, J.; Thurner, S.; Klimek, P.; Kautzky-Willer, A. Diagnosis of osteoporosis in statin-treated patients is dose-dependent. Ann. Rheum. Dis. 2019, 78, 1706-1711. [CrossRef] [PubMed]

13. Fischer, S.; Julius, U. Management of patients with statin intolerance. Atheroscler. Suppl. 2017, 30, 33-37. [CrossRef]

14. Saxon, D.R.; Eckel, R.H. Statin intolerance: A literature review and management strategies. Prog. Cardiovasc. Dis. 2016, 59, 153-164. [CrossRef] [PubMed]

15. Cannon, C.P.; Blazing, M.A.; Giugliano, R.P.; McCagg, A.; White, J.A.; Theroux, P.; Darius, H.; Lewis, B.S.; Ophuis, T.O.; Jukema, J.W.; et al. Ezetimibe added to statin therapy after acute coronary syndromes. N. Engl. J. Med. 2015, 372, 2387-2397. [CrossRef] [PubMed]

16. Avorn, J.; Monette, J.; Lacour, A.; Bohn, R.L.; Monane, M.; Mogun, H.; LeLorier, J. Persistence of use of lipid-lowering medicationsA cross-national study. JAMA 1998, 279, 1458-1462. [CrossRef]

17. Colantonio, L.D.; Rosenson, R.S.; Deng, L.; Monda, K.L.; Dai, Y.; Farkouh, M.E.; Safford, M.M.; Philip, K.; Mues, K.E.; Muntner, P. Adherence to statin therapy among us adults between 2007 and 2014. J. Am. Heart Assoc. 2019, 8, e010376. [CrossRef]

18. Rauch, B.; Riemer, T.; Schwaab, B.; Schneider, S.; Diller, F.; Gohlke, H.; Schiele, R.; Katus, H.; Gitt, A.; Senges, J.; et al. Short-term comprehensive cardiac rehabilitation after AMI is associated with reduced 1-year mortality: Results from the OMEGA study. Eur. J. Prev. Cardiol. 2014, 21, 1060-1069. [CrossRef]

19. Anderson, L.J.; Taylor, R.S. Cardiac rehabilitation for people with heart disease: An overview of Cochrane systematic reviews. Int. J. Cardiol. 2014, 177, 348-361. [CrossRef]

20. Kim, C.; Youn, J.E.; Choi, H.E. The effect of a self exercise program in cardiac rehabilitation for patients with coronary artery disease. Ann. Rehabil. Med. 2011, 35, 381-387. [CrossRef]

21. Kwan, G.; Balady, G.J. Cardiac rehabilitation 2012: Advancing the field through emerging science. Circulation 2012, 125, e369-e373. [CrossRef]

22. Gielen, S.; Laughlin, M.H.; O'Conner, C.; Duncker, D.J. Exercise training in patients with heart disease: Review of beneficial effects and clinical recommendations. Prog. Cardiovasc. Dis. 2015, 57, 347-355. [CrossRef] [PubMed]

23. Anderson, L.; Thompson, D.R.; Oldridge, N.; Zwisler, A.D.; Rees, K.; Martin, N.; Taylor, R.S. Exercise-based cardiac rehabilitation for coronary heart disease. Cochrane Database Syst. Rev. 2016. [CrossRef]

24. Rauch, B.; Davos, C.H.; Doherty, P.; Saure, D.; Metzendorf, M.I.; Salzwedel, A.; Voller, H.; Jensen, K.; Schmid, J.P.; Cardiac Rehabilitation Section in EAPC; et al. The prognostic effect of cardiac rehabilitation in the era of acute revascularisation and statin therapy: A systematic review and meta-analysis of randomized and non-randomized studies-The cardiac rehabilitation outcome study (CROS). Eur. J. Prev. Cardiol. 2016, 23, 1914-1939. [CrossRef] [PubMed]

25. Junger, C.; Rauch, B.; Schneider, S.; Liebhart, N.; Rauch, G.; Senges, J.; Bestehorn, K. Effect of early short-term cardiac rehabilitation after acute ST-elevation and non-ST-elevation myocardial infarction on 1-year mortality. Curr. Med. Res. Opin. 2010, 26, 803-811. [CrossRef] [PubMed] 
26. Schlitt, A.; Wischmann, P.; Wienke, A.; Hoepfner, F.; Noack, F.; Silber, R.E.; Werdan, K. Rehabilitation in patients with coronary heart disease: Participation and its effect on prognosis. Dtsch. Arztebl. Int. 2015, 112, 527-534. [CrossRef]

27. Schwaab, B.; Waldmann, A.; Katalinic, A.; Sheikhzadeh, A.; Raspe, H. In-patient cardiac rehabilitation versus medical care-A prospective multicentre controlled 12 months follow-up in patients with coronary heart disease. Eur. J. Prev. Cardiol. 2011, 18, 581-586. [CrossRef]

28. Haffner, S.M.; Alexander, C.M.; Cook, T.J.; Boccuzzi, S.J.; Musliner, T.A.; Pedersen, T.R.; Kjekshus, J.; Pyorala, K. Reduced coronary events in simvastatin-treated patients with coronary heart disease and diabetes or impaired fasting glucose levels: Subgroup analyses in the scandinavian simvastatin survival study. Arch. Intern. Med. 1999, 159, 2661-2667. [CrossRef]

29. Dornquast, C.; Kroll, L.E.; Neuhauser, H.K.; Willich, S.N.; Reinhold, T.; Busch, M.A. Regional differences in the prevalence of cardiovascular disease. Dtsch. Arztebl. Int. 2016, 113, 704-711. [CrossRef] 